\title{
Faktor Maternal Terhadap Kejadian BBLR
}

\author{
${ }^{1}$ Anjelina Puspita Sari ${ }^{*},{ }^{2}$ Romlah, ${ }^{3}$ Theresia Anita \\ 1,2,3Prodi DIII Kebidanan, Universitas Katolik Musi Charitas Palembang \\ *Email: angelinaps88@gmail.com
}

\section{Kata kunci : \\ Faktor maternal,}

BBLR

\section{Keywords :}

Maternal factors, LBW

Info Artikel:

Tanggal dikirim:

16 Februari 2021

Tanggal direvisi:

5 Maret 2021

\section{Tanggal diterima :}

16 Maret 2021

\section{DOI Artikel:}

10.33862/citradelima.v5i

1.210

Halaman: $1-5$

\begin{abstract}
Abstrak
Bayi Berat Lahir Rendah (BBLR) merupakan salah satu penyebab kematian bayi yang menimbulkan berbagai macam masalah kesehatan. Data Dinas Kesehatan Kota Palembang tahun 2017 terdapat 29 kasus kematian bayi yang salah satu penyebabnya adalah BBLR. Penelitian ini bertujuan untuk mengetahui hubungan faktor maternal dengan kejadian BBLR. Metode: Jenis penelitian menggunakan analitik obsevasional dengan menggunakan desain cross sectional. Penelitian ini dilakukan sejak MeiSeptember 2019, dengan jumlah sampel sebanyak 52 responden. Data diambil dengan observasi data retrospektif catatan medik responden. Teknik Analisa menggunakan uji Chi-Square. Hasil uji statistic ada hubungan yang signifikan antara usia terhadap kejadian BBLR ( $\mathrm{p}$ value $=0.012$ ), ada hubungan sginifikan antara paritas dengan BBLR ( $\mathrm{p}$ value $=0.047)$, dan tidak terdapat hubungan yang signifikan antara riwayat BBLR pada anak sebelumnya dengan kejadian BBLR ( $\mathrm{p}$ value $=0.094$ ). Kesimpulan dalam penelitian ini BBLR menimbulkan berbagai masalah kesehatan pada bayi baru lahir karena itu, diperlukan pengawasan lebih ketat terhadap ibu hamil terutama pada ibu hamil yang termasuk dalam faktor resiko.
\end{abstract}

\section{Maternal Factors Against The Incidence Of LBW}

\begin{abstract}
Background: Low Birth Weight Infants (LBW) is one of the causes of infant mortality which causes various health problems. Palembang City Health Office in 2017 stated that 29 cases of infant mortality, one of which was LBW. This study aimed to determine the relationship between maternal factors with the incidence of LBW. Methods: This study was an obsevastional with a cross sectional design. This study was conducted from MaySeptember 2019, with a samples was 52 respondents. Samples were collected by observing retrospective data from the respondent's medical records. Data analysis technique was the Chi-Square. Results: The results showed a significant relationship between age and LBW ( $\mathrm{pv}=0.012)$, the parity with LBW were significantly related $(\mathrm{pv}=0.047)$, and there was no significant relationship the previous LBW history with LBW (pv =0.094). Conclusion: LBW raises various health problems in newborns. Therefore, it requires tighter supervision of pregnant women, especially pregnant women who are included in the risk factors.
\end{abstract}

\section{PENDAHULUAN}

Angka Kematian Bayi (AKB) pada tahun 2018 di Dunia mencapai 29/1.000 Kelahiran Hidup (KH) atau sekitar 4 juta bayi yang meninggal (World Health Organization, 2019). Angka ini masih belum memenuhi target SDG'S yaitu menurunkan AKB menjadi 25/1.000 KH (World Health Organization, 2019). Survei Demografi dan Kesehatan Indonesia (SDKI) pada tahun 2017 jumlah AKB 24/1.000 KH (Kementerian Kesehatan RI, 2018). Data AKB di Provinsi Sumatera Selatan mengalami peningkatan dari
87/16.210 KH pada tahun 2016 menjadi 98/161.210 KH pada tahun 2017. Data AKB di kota Palembang mencapai 29 kasus dengan penyebab kematian adalah diare, pneumonia, asfiksia, BBLR, kelainan kongenital dan lainnya (Dinas Kesehatan Kota Palembang, 2018).

Bayi Berat Lahir Rendah (BBLR) merupakan bayi dengan berat badan lahir $<2500$ gram tanpa memandang usia kehamilannya. Klasifikasi berat badan bayi yaitu bayi berat lahir rendah dengan berat $<2500$ gram, bayi berat lahir sedang yaitu 2500-3999 gram, dan berat lebih yaitu $\geq 4000$ gram (Kementerian

http://jurnalilmiah.stikescitradelima.ac.id/index.php/JI Vol. 5 No. 1 Juli 2021 
Kesehatan RI, 2018). Kejadian BBLR merupakan salah satu penyebab lannsung kematian bayi. Dampak tidak langsung yang ditimbulkan dapat berupa dampak jangka Panjang seperti keterlambatan pertumbuhan dan perkembangan pada masa anak-anak (Nengsih, et al 2016 ; Santri, et al 2014).

Salah satu penyumbang penyebab kematian bayi adalah BBLR. BBLR sendiri banyak dipengaruhi oleh berbagai macam faktor salah satunya adalah faktor maternal atau faktor ibu itu sendiri. Faktor maternal memiliki pengaruh terhadap berat badan bayi yang dilahirkan karena pada saat didalam kandungan janin mendapatkan kebutuhannya untuk bertahan hidup dari ibunya, sehingga kondisi ibu sendiri berpengaruh terhadap pertumbuhan dan perkembangan janin. Faktor maternal meliputi usia ibu ketika terjadi kehamilan, status paritas ibu yaitu jumlah atau banyaknya anak yang dilahirkan, dan riwayat kehamilan ibu dengan BBLR (Sharon, et al 2012 ; Kusumawati, 2017).

Penelitian lain menyatakan bahwa terdapat hubungan yang signifikan antara umur dan paritas dengan kejadian BBLR di RSUD Solok (Restiani and Arif, 2013). Penelitian ini bertentangan dengan penelitian Salawati yang menyatakan bahwa tidak ada hubungan yang bermakna antara paritas dengan kejadian BBLR (Salawati, 2012).

\section{METODE}

Jenis penelitian ini merupakan jenis penelitian analitik kuantitatif dengan menggunakan desain cross sectional. Penelitian ini bertempat di PMB 11 Ilir Timur Palembang. Data diambil dengan data retrospektif catatan medik responden. Teknik pengambilan sampel menggunakan total sampling/ Semua pasien yang bersalin di PMB dari tahun 20182019 yaitu 52 responden yang telah memenuhi kriteria inklusi yaitu ibu dengan riwayat kehamilan dan persalinan normal berdasarkan catatan medik responden, responden dibagi dengan rentang usia resiko tinggi (<20 tahun/ >35 tahun) dan resiko rendah (20- $\geq 35$ tahun), status paritas tinggi ( $\geq 4$ anak) dan rendah (1-3 anak), riwayat BBLR pada kehamilan sebelumnya (ada/tidak). Kriteria ekslusi dalam penelitian ini yaitu kehamilan dengan komplikasi. Teknik Analisa data menggunakan uji statistk Chi-Square.

\section{HASIL DAN PEMBAHASAN}

Hasil

Tabel 1. Distribusi Karakteristik Responden

\begin{tabular}{lcc}
\hline Karakteristik & F & \% \\
\hline Umur & & \\
Resiko Tinggi & 12 & 23.1 \\
Resiko Rendah & 40 & 76.9 \\
\hline Paritas & & \\
Tinggi & 11 & 21.2 \\
Rendah & 41 & 78.8 \\
\hline Riwayat BBLR & & \\
Ada & 9 & 23.1 \\
Tidak Ada & 43 & 76.9 \\
\hline
\end{tabular}

Karakteristik responden berdasarkan Tabel 1 . diketahui bahwa jumlah responden yang terbanyak pada rentang usia resiko rendah yaitu 40 responden dengan presentase $76.9 \%$, dan diikuti responden dengan usia resiko tinggi sebanyak 12 responden dengan presentase $23,1 \%$. Status paritas responden terbanyak yaitu paritas rendah yang berjumlah 41 responden dengan presentase $78.8 \%$, dan diikuti paritas tinggi yang berjumlah 11 responden dengan presentase $21.2 \%$. Tabel 1. juga menjelaskan bahwa mayoritas responden tidak memiliki riwayat BBLR pada persalinan yang lalu berjumlah 43 responden dengan presentase $76.9 \%$, dan diikuti dengan responden yang memiliki riwayat BBLR yang berjumlah 9 orang dengan presentase $23,1 \%$.

Tabel 2. Usia dengan Kejadian BBLR

\begin{tabular}{lcccccc}
\hline \multirow{2}{*}{ Usia } & \multicolumn{2}{c}{ BBLR } & \multicolumn{2}{c}{ TOTAL } & OR & P \\
\cline { 2 - 5 } & YA & TDK & n & \% & & \\
\cline { 2 - 5 } & $\mathrm{n}$ & $\mathrm{n}$ & & & & \\
\hline Resiko & 6 & 6 & 12 & 23 & 5.667 & 0.0 \\
Tinggi & & & & .1 & $(1.361$ & 12 \\
\hline Resiko & 6 & 34 & 40 & 76 & $-23.5)$ & \\
Rendah & & & & .9 & & \\
\hline
\end{tabular}

Berdasarkan Tabel 2. menunjukan bahwa responden dengan usia resiko tinggi yang mengalami BBLR berjumlah 6 responden dan yang tidak mengalami BBLR berjumlah 6 responden. Responden dengan usia resiko rendah yang mengalami BBLR berjumlah 6 responden, dan yang tidak mengalami BBLR berjumlah 34 responden.

Berdasarkan uji Chi-Square didapatkan $P$ Value 0.012 lebih kecil dari 0.05, maka ada hubungan signifikan antara usia dengan kejadian BBLR. Dari

http://jurnalilmiah.stikescitradelima.ac.id/index.php/JI Vol. 5 No. 1 Juli 2021 
analisis keeratan hubungannya menunjukkan nilai Odd Ratio (OR) 5.667 yang berarti bahwa responden dengan usia resiko tinggi 5.667 kali memiliki resiko terjadinya BBLR dibandingkan dengan responden berusia rsiko rendah.

Tabel 3. Paritas dengan Kejadian BBLR

\begin{tabular}{|c|c|c|c|c|c|c|}
\hline \multirow[t]{3}{*}{ Paritas } & \multicolumn{2}{|c|}{ BBLR } & \multicolumn{2}{|c|}{ TOTAL } & \multirow[t]{2}{*}{ OR } & \multirow[t]{2}{*}{$\mathbf{P}$} \\
\hline & YA & TDK & $\mathbf{n}$ & $\%$ & & \\
\hline & $\mathrm{n}$ & $\mathrm{n}$ & & & & \\
\hline \multirow[t]{2}{*}{ Tinggi } & 5 & 6 & 11 & 21 & \multirow{3}{*}{$\begin{array}{l}4.048 \\
(0.960 \\
- \\
17.06 \\
4)\end{array}$} & \multirow{3}{*}{$\begin{array}{l}0.0 \\
47\end{array}$} \\
\hline & & & & .2 & & \\
\hline Rendah & 7 & 34 & 41 & $\begin{array}{l}78 \\
.8\end{array}$ & & \\
\hline
\end{tabular}

Berdasarkan Tabel 3. menunjukan bahwa responden dengan paritas tinggi yang mengalami BBLR berjumlah 5 responden dan yang tidak mengalami BBLR berjumlah 6 responden. Responden dengan paritas rendah yang mengalami BBLR berjumlah 7 responden, dan yang tidak mengalami BBLR berjumlah 34 responden.

Berdasarkan uji Chi-Square didapatkan $P$ Value 0.047 lebih kecil dari 0.05, maka ada hubungan signifikan antara paritas dengan kejadian BBLR. Dari analisis keeratan hubungannya menunjukkan nilai $O d d$ Ratio (OR) 4.048 yang berarti bahwa responden dengan paritas tinggi 4.048 kali memiliki resiko terjadinya BBLR dibandingkan dengan responden paritas rendah.

\section{Tabel 4. Riwayat BBLR dengan Kejadian BBLR}

\begin{tabular}{|c|c|c|c|c|c|c|}
\hline \multirow{3}{*}{$\begin{array}{c}\text { Riwa } \\
\text { yat }\end{array}$} & \multicolumn{2}{|c|}{ BBLR } & \multicolumn{2}{|c|}{ TOTAL } & \multirow[t]{2}{*}{ OR } & \multirow[t]{2}{*}{$\mathbf{P}$} \\
\hline & YA & TDK & $\mathbf{n}$ & $\%$ & & \\
\hline & $\mathrm{n}$ & $\mathrm{n}$ & & & & \\
\hline \multirow[t]{2}{*}{$\mathrm{Ya}$} & 4 & 5 & 9 & 23 & \multirow{2}{*}{$\begin{array}{l}3.50 \\
(0.763\end{array}$} & \multirow{2}{*}{$\begin{array}{l}0.0 \\
94\end{array}$} \\
\hline & & & & .1 & & \\
\hline Tidak & 8 & 35 & 43 & $\begin{array}{l}76 \\
.9\end{array}$ & $\begin{array}{l}- \\
16.04 \\
6)\end{array}$ & \\
\hline
\end{tabular}

Berdasarkan Tabel 4. Menunjukan bahwa responden dengan riwayat BBLR yang mengalami BBLR berjumlah 4 responden, dan yang tidak mengalami BBLR berjumlah 5 responden. Responden yang tidak mempunyai riwayat BBLR tapi mengalami BBLR berjumlah 8 responden, dan yang tidak mengalami BBLR berjumlah 35 responden.

Berdasarkan uji Chi-Square didapatkan $P$ Value 0.094 lebih besar dari 0.05, maka tidak ada hubungan signifikan antara riwayat BBLR dengan kejadian BBLR. Dari analisis keeratan hubungannya menunjukkan nilai Odd Ratio (OR) 3.50 yang berarti bahwa responden dengan riwayat BBLR 3.50 kali memiliki resiko terjadinya BBLR dibandingkan dengan responden yang tidak memiliki riwayat BBLR.

\section{Pembahasan}

Kehamilan pada remaja (10-19 tahun) dan kehamilan pada wanita tua ( $\geq 35$ tahun) berbahaya bagi kesehatan ibu maupun janin yang dikandung (Saloojee H., 2015). Resiko kematian perinatal lebih tinggi terjadi pada wanita primipara berusia tua (35-39 tahun) dan semakin meningkat lagi pada wanita berusia $\geq 40$ tahun (Klemmetti, et al 2013). Ibu terlalu muda muda dan ibu usia tua mempunyai resiko peningkatan berat lahir rendah, kelahiran prematur, stunting pada bayi, serta IQ yang kurang saat sekolah (Fall et al., 2015). hal ini juga dikarenakan bayi tidak mendapatkan ASI dimana faktor usia ibu juga siginfikan berpengaruh pada produksi ASI (Romlah dan Sari, 2020).

Usia ibu > 35 tahun beresiko lebih tinggi mengalami kejadian persalinan dengan BBLR dari pada ibu yang berada di usia reproduktif, hal ini dikarenakan ibu lebih rentan terkena penyakit degenaratif (Khoiriah, 2017). Yang dapat berdampak pada kondisi kesehatan ibu, apabila ibu mengalami kehamilan maka bisa mempengaruhi kehamilan, persalinan termasuk BBLR (Sembiring, Pratiwi and Sarumaha, 2019). Ibu usia > 35 tahun berpeluang 10,7 kali untuk melahirkan bayi dengan BBLR dibanding dengan ibu berusia 20-35 tahun (Salawati, 2012).

Ibu hamil dengan rentang usia 35-39 tahun cenderung beresiko untuk mengalami persalinan bayi lahir mati, bayi berat lahir rendah, dan kelahiran prematur di Negara-negara berpenghasilan tinggi (Carolan and Franskowska, 2011 ; Ngowa, et al 2013 ; Kenny et al., 2013). Penelitian ini sejalan juga dengan penelitian Goisis et al yang menyatakan bahwa komplikasi kehamilan dan masalah kesehatan meningkat seiring bertambahnya usia ibu, karena umur ibu yang lebih tua beresiko menghadapi lebih banyak masalah kesehatan baik sebelum hamil maupun selama hamil yang dapat berdampak pada kondisi janin dibandingkan dengan ibu usia reproduktif (Goisis et al., 2017).

Paritas tinggi menyebabkan terganggunya fungsi plasenta dalam memberikan nutrisi ke janin akibat seringnya ibu melahirkan, kondisi ini akan berdampak pada terganggunya pertumbuhan janin (Khoiriah, 2017). Ibu dengan paritas tinggi fungsi uterus sudah mengalami kemunduran karena kondisi uterus yang sudah tidak subur lagi menyebabkan fungsi dari http://jurnalilmiah.stikescitradelima.ac.id/index.php/JI Vol. 5 No. 1 Juli 2021 
plasenta untuk mensuplai oksigen dan nutrisi terganggu pula. Paritas yang tinggi juga tidak hanya berdampak pada ibu tapi juga berdampak pada bayi yang dikandung. Ibu yang terlalu sering mengalami persalinan beresiko untuk melahirkan bayi dengan BBLR atau bayi yang cacat (Sembiring et al., 2019).

Penelitian ini sejalan juga dengan penelitian Wahyuningrum yang menyatakan bahwa ada hubungan bermakna antara paritas dengan kejadian berat bayi lahir rendah dimana paritas multipara beresiko lebih tinggi untuk mengalami BBLR (Wahyuningrum, et al., 2016). Penelitian Setiati dan Rahayu juga menyatakan paritas tinggi juga berhubungan bermakna dengan kejadian BBLR (Setiati and Rahayu, 2017).

Penelitian ini sejalan dengan penelitian Setiati dan Rahayu yang menyatakan bahwa tidak ada hubungan signifikan antara riwayat ibu melahirkan BBLR terhadap kejadian BBLR, hal ini dikarenakan pengalaman yang sudah dialami ibu dapat dijadikannya pembelajaran sehingga pada persalinan berikutnya kejadian BBLR tidak terulang lagi (Setiati and Rahayu, 2017).

Ibu yang memiliki pengalaman melahirkan BBLR sedikit banyak mempunyai pengalaman dikarenakan bayi dengan BBLR perawatan sehari-harinya berbeda dengan bayi berat normal. Petugas kesehatan juga melakukan pemantauan dan evaluasi sampai bayi beratnya lebih dari 2500 gram. Pengalaman yang dimiliki ini membuat ibu untuk lebih berhati-hati pada kehamilan berikutnya dan petugas kesehatan juga terus melakukan pemantauan agar tidak terjadi BBLR pada persalinan berikutnya, sehingga pada penelitian ini tidak ada hubungan yang signifikan antara riwayat ibu dengan BBLR terhadap kejadian BBLR.

\section{SIMPULAN}

Ada hubungan signifikan antara usia dengan kejadian BBLR.

Ada hubungan signifikan antara paritas dengan kejadian BBLR.

Tidak ada hubungan signifikan antara riwayat BBLR dengan kejadian BBLR.

\section{DAFTAR PUSTAKA}

Carolan M and Franskowska DMN (2011) 'Advanced maternal age and adverse perinatal outcome: A review of the evidence', PubMed, 27(6), pp. 793-801. Available at: https://pubmed.ncbi.nlm.nih.gov/20888095/.

Dinas Kesehatan Kota Palembang (2018) Profil Kesehatan Tahun 2017. Jakarta: Kementrian Kesehatan RI.
Fall, C. H. D. et al. (2015) 'Association between maternal age at childbirth and child and adult outcomes in the offspring: A prospective study in five low-income and middle-income countries (COHORTS collaboration)', The Lancet Global Health, 3(7), pp. e366-e377. doi: 10.1016/S2214-109X(15)00038-8.

Goisis, A. et al. (2017) 'Advanced Maternal Age and the Risk of Low Birth Weight and Preterm Delivery: A Within-Family Analysis Using Finnish Population Registers', American Journal of Epidemiology, 186(11), pp. 12191226. doi: 10.1093/aje/kwx177.

Kementerian Kesehatan RI (2018) Profil Kesehatan Indonesia Tahun 2013. Jakarta: Kementerian Kesehatan RI.

Kenny, L. C. et al. (2013) 'Advanced Maternal Age and Adverse Pregnancy Outcome: Evidence from a Large Contemporary Cohort', PLoS ONE, 8(2), pp. 1-9. doi: 10.1371/journal.pone.0056583.

Khoiriah, A. (2017) 'Hubungan Antara Usia Ibu dan Paritas Ibu Bersalin dengan Berat Bayi Lahir Rendah (BBLR) Di RS. Siti Khadijah Palembang', Jurnal Kesehatan, 8(2), pp. 310 314. Available at: http://dx.doi.org/10.35842/jkry.v5i2.201.

Klemmetti R., Gisler M., Sainio S., H. E. (2013) 'Associations of maternal age with maternity care use and birth outcomes in primiparous women: a comparison of results in 1991 and 2008 in Finland', Acta Obstet Gynecol Scand, 75, pp. 19-27. doi: https://doi.org/10.1111/1471-0528.12415.

Kusumawati, E. (2017) 'Tinjauan Sistematis Terhadap Faktor Risiko Kejadian Berat Badan Lahir Rendah di Indonesia', Jurnal of Health Science and Prevention, 1(1), pp. 38-44. Available at: http://jhsp.uinsby.ac.id/index.php/jhsp/article/do wnload/10/12/.

Ngowa JDK, Ngassam A, Dohbit JS, Nzedjom C, K. J. (2013) 'Pregnancy outcome at advanced maternal age in a group of African women in two teaching hospitals in Yaounde, Cameroon', Pan Afr Med J, 14, p. 134. doi: 10.11604/pamj.2013.14.134.2315.

Restiani, R. and Arif, A. (2013) 'Hubungan Umur Dan Paritas Dengan Kejadian Berat Bayi Lahir Rendah (BBLR)', E-Jurnal Obstretika, 1(1), pp. 22-37.

Romlah dan Sari, A. (2020) 'Konsumsi Tablet Besi Terhadap Kadar Hemoglobin Ibu Hamil Trimester Dua', JPP (Jurnal Kesehatan Poltekkes Palembang), 15(1), pp. 45-51. doi: 10.36086/jpp.v15i1.466.

Salawati, L. (2012) 'Hubungan Usia, Paritas Dan Pekerjaan Ibu Hamil Dengan Bayi Berat Lahir Rendah', Jurnal Kedokteran Syiah Kuala, 12(3), pp. 138-142. doi:

http://jurnalilmiah.stikescitradelima.ac.id/index.php/JI Vol. 5 No. 1 Juli 2021 
10.24815/jks.v12i3.2745.

Saloojee H., and C. H. (2015) 'Maternal age matters: for a lifetime, or longer', PubMed, 3(7), pp. e342-e343. doi: https://doi.org/10.1016/S2214109X(15)00034-0.

Santri, A., Idriansari, A. and Girsang, B. M. (2014) 'Faktor-faktor yang mempengaruhi pertumbuhan dan perkembangan anak usia toddler [1-3 tahun] dengan riwayat bayi berat lahir rendah', ilmu kesehatan Masyarakat, 5(1), p. 64. Available at: https://media.neliti.com/media/publications/579 91-ID-the-factors-affecting-growth-anddevelop.pdf.

Sembiring, J. B., Pratiwi, D. and Sarumaha, A. (2019) 'Hubungan Usia, Paritas dan Usia Kehamilan dengan Bayi Berat Lahir Rendah di Rumah Sakit Umum Mitra Medika Medan', Jurnal Bidan Komunitas, 2(1), p. 38. doi: 10.33085/jbk.v2i1.4110.

Setiati, A. R. and Rahayu, S. (2017) 'Faktor Yang Mempengaruhi Kejadian BBLR (Berat Badan Lahir Rendah) Di Ruang Perawatan Intensif
Neonatus RSUD DR Moewardi Di Surakarta', (Jkg) Jurnal Keperawatan Global, 2(1), pp. 920. doi: 10.37341/jkg.v2i1.27.

Sharon, J., Reeder, R.N., Leonide, L. . et al (2012) Keperawatan Maternita: Kesehatan Wanita, Bayi, \& Keluarga (Maternity Nursing: Family, Newborn, and Women's Health Care): Bayi Baru Lahir Berisiko Tinggi: Gangguan Usia Gestasi dan Berat Badan Lahir. Edisi 8. Volume 2. Jakarta: EGC.

Wahyuningrum, T., Saudah, N. and Wahyu Novitasari, W. (2016) 'Hubungan Paritas Dengan Berat Bayi Lahir Di Rumah Sakit Umum Daerah Dr. Wahidin Sudiro Husodo Mojokerto', Midwiferia, 1(2), p. $87 . \quad$ doi: 10.21070/mid.v1i2.352.

World Health Organization (2019a) Maternal Mortality. Geneva: World Health Organization.

World Health Organization (2019b) Monitoring Health for the SDGs. Geneva: World Health Organization. 